\title{
Correction to: The effect of functionalized titanium dioxide nanotube reinforcement on the water sorption and water solubility properties of flowable bulk-fill composite resins
}

\author{
Mustafa Kutay Karaca ${ }^{1} \cdot$ Ozge Kam Hepdeniz $^{2}$ [D $\cdot$ Banu Esencan Turkaslan ${ }^{3} \cdot$ Osman Gurdal $^{4}$
}

Published online: 17 February 2022

(c) The Author(s), under exclusive licence to The Society of The Nippon Dental University 2022

\section{Correction to: Odontology \\ https://doi.org/10.1007/s10266-021-00664-7}

The Acknowledgements section was missing from this article and should have read "This study was supported by the Suleyman Demirel University Scientific Research Projects Foundation (TDH-2018-6820)".

Publisher's Note Springer Nature remains neutral with regard to jurisdictional claims in published maps and institutional affiliations.

The original article can be found online at https://doi.org/10.1007/ s10266-021-00664-7.

Ozge Kam Hepdeniz

ozgekam@gmail.com

1 Izmir, Turkey

2 Faculty of Dentistry, Department of Restorative Dentistry, Suleyman Demirel University, Isparta, Turkey

3 Faculty of Engineering, Department of Chemical Engineering, Suleyman Demirel University, Isparta, Turkey

4 Faculty of Medicine, Department of Biostatistics and Medical Informatics, Suleyman Demirel University, Isparta, Turkey 